IZA DP No. 5059

A Political Economy of the Immigrant Assimilation: Internal Dynamics

Gil S. Epstein

Ira N. Gang

July 2010 


\title{
A Political Economy of the Immigrant Assimilation: Internal Dynamics
}

\author{
Gil S. Epstein \\ Bar-llan University, \\ CReAM and IZA \\ Ira N. Gang \\ Rutgers University, \\ CReAM and IZA
}

\section{Discussion Paper No. 5059}

July 2010

\author{
IZA
}

P.O. Box 7240

53072 Bonn

Germany

Phone: +49-228-3894-0

Fax: +49-228-3894-180

E-mail: iza@iza.org

Any opinions expressed here are those of the author(s) and not those of IZA. Research published in this series may include views on policy, but the institute itself takes no institutional policy positions.

The Institute for the Study of Labor (IZA) in Bonn is a local and virtual international research center and a place of communication between science, politics and business. IZA is an independent nonprofit organization supported by Deutsche Post Foundation. The center is associated with the University of Bonn and offers a stimulating research environment through its international network, workshops and conferences, data service, project support, research visits and doctoral program. IZA engages in (i) original and internationally competitive research in all fields of labor economics, (ii) development of policy concepts, and (iii) dissemination of research results and concepts to the interested public.

IZA Discussion Papers often represent preliminary work and are circulated to encourage discussion. Citation of such a paper should account for its provisional character. A revised version may be available directly from the author. 
IZA Discussion Paper No. 5059

July 2010

\section{ABSTRACT}

\section{A Political Economy of the Immigrant Assimilation: Internal Dynamics*}

Within immigrant society different groups wish to help the migrants in different ways immigrant societies are multi-layered and multi-dimensional. We examine the situation where there exists a foundation that has resources and that wishes to help the migrants. To do so they need migrant groups to invest effort in helping their country-folk. Migrant groups compete against one another by helping their country-folk and to win grants from the foundation. We develop a model that considers how such a competition affects the resources invested by the groups' supporters and how beneficial it is to immigrants. We consider two alternative rewards systems for supporters - absolute and relative ranking - in achieving their goals.

JEL Classification: F22, J0

Keywords: migration, assimilation, political economy

Corresponding author:

Gil S. Epstein

Department of Economics

Bar-Ilan University

52900 Ramat-Gan

Israel

E-mail: epsteig@mail.biu.ac.il

\footnotetext{
* Financial support from the Adar Foundation of the Economics Department at Bar-llan University is gratefully acknowledged.
} 


\section{INTRODUCTION}

Immigrant societies are multi-layered and multi-dimensional offering many perspectives, some of which may come into conflict with others, leading to the development of rivalrous strategies, at least partly overlapping loyalties of supporters, and the necessity of laying claim to having the bigger impact. Supporters of each perspective invest resources and effort into convincing the general body of immigrants of the virtue of their point of view. These rivalries can be characterized as contests - each side struggles, investing substantial effort, pushing their own agenda in helping their immigrant society.

In our society there exists a foundation that has resources and wishes to help migrants. To help migrants the foundation works indirectly, offering grants to groups who directly invest efforts to help migrants (for example in the USA we have the MacArthur Foundation and the Ford Foundation that want to help immigrants.) The foundation offers a prize (grant) for which the groups compete. The competition is such that the one that invests more resources in helping migrants has a higher probability of winning and obtaining even more resources. We address how the foundation elicits the most effort from the different "grass roots" groups.

Each group - that is, a part of immigrant society that possesses a common perspective and acts to achieve it - wants the authority and rewards for implementing its own plan, believing its proposal will best help its countrymen. The groups may aim to achieve a certain degree of assimilation on the part of immigrants, though each group has its own strategy. They may differ on the degree of cultural identity they want to maintain with their birthplace (see, for example, Alesina and La Ferrara, 2000, Anas, 2002, Bisin and Verdier, 2000, Dustmann, Fabbri and Preston, 2004, Gang and Zimmermann, 2000, Kahanec, 2006, and Lazear, 1999). Each group seeks to lead immigrant society, and capturing the prize rewarded by the foundation. The key to our analysis of who wins the contest is the contest rule structure.

Studies of immigrants around the world show, with few exceptions, their earnings are substantially below those of comparable majority workers (Altonji and Blank 1999, Blau and Kahn, 1997, 2006, 2007, Smith and Welch, 1989, Bhaumik, Gang and Yun, 2006). Partly, this reflects a failure on the part of the immigrants to undertake the effort to assimilate with the local community (Constant, Gataullina and Zimmermann, 2008). "Lack of effort" can arise from the desire to maintain a cultural heritage or separate identity which would be lost or reduced if the group assimilated. The failure to take active steps to assimilate can also arise in the face of high 
adjustment costs, such as inadequate language skills, intergenerational familial conflicts, and, in the case of immigrants, lack of knowledge about the host country labor market (Chiswick and Miller, 1995, 1996, Bauer, Epstein and Gang, 2005). Yet for immigrants and their descendants, as length of time in the host country increases, assimilation generally creeps in and various immigrant labor market indicators approach those of comparable majority workers. On occasion, they outperform the native-born (Chiswick, 1977, Deutsch, Epstein and Lecker, 2006).

Efforts made to assimilate, and time, are two elements working to bring immigrants onto line with the native-born. A third element, the degree to which the local society welcomes immigrants, also plays a role. Often, the local society is less than welcoming, blaming migrants for depressing wages and displacing native-born workers - i.e., causing unemployment. This presumption has very strong policy implications and is implicit, for example, in the calls for increased regulation of immigration heard worldwide. Yet, there is mixed evidence on the impact of immigrants on the local's wages and employment - it depends on whether they are substitutes or complements with respect to the skills and other attributes they bring to the labor market (Gang and Rivera-Batiz 1994, Gang, Rivera-Batiz and Yun 2002 and this volume). Whether immigrants actually lower wages and increase employment, or not, the perception exists that they do so. Because of this perception the local population may take active steps to discourage immigrants' assimilation - discrimination, isolation, and so on. For this reason effort in needed to decrease the barriers between the local population and the migrants.

Epstein and Gang (2009a) are interested in why migrants are so often at a disadvantage relative to the native-born, the circumstances under which their status changes or stagnates over time, and role public policy can play. Often the efforts of the immigrants and the local population are mediated through political institutions. These institutions exist in both worlds. They could be, for example, political parties, trade organizations, unions, or thugs. These are organizations that are able to overcome the free-rider problem individual members of each group have in moving from the actions they desire to take, to actually taking the actions. Yet, while an organization's purpose may be to represent the members of their group, the interests' of the organization and that of its members do not always coincide. Assimilation efforts by migrants, harassment by the native-born and time are the three elements that determine how well migrants do. Epstein and Gang (2009a) examine the consequences for these of increases in the numbers of immigrants, time, and the role of politics. They construct a model in which there are four 
actors: the members of the majority and the organization that represents them, and members of the minority and the organization that represents them. Over time, the organization representing the migrants and immigrants themselves may exhibit different interests in assimilating and in maintaining their cultural identity. They discuss how this affects the migrants' position over time and discuss the public policy implications of the model.

In this paper, we describe and compare two mechanisms for rewarding groups for their efforts. Absolute ranking is a contest between the groups where the winning one receives all the grants - those who put forth the most effort win. In this situation the simultaneous bidders are the groups, and their bids are the actions/investments they undertake. Those that take the most action, or those that are perceived to have taken the most action, win, and acquire all the grant. On the other hand, in relative ranking the groups compete against each other and obtain grant relative to the amount of effort invested in the contest. This can be seen as a lottery contest in which each obtains grant proportional to the effort invested. In both cases, in equilibrium, the grant obtained is a function of the efforts invested.

The structure of the contest can be a key element determining the direction immigrant society goes. The foundation wishes to maximize the efforts made by the groups to help immigrant society. We develop economic theory that considers how such competition affects the resources invested by each group and the performance of immigrant society. We wish to see how these two alternative rewards systems - absolute and relative ranking - affect the implementation and achievement of the foundations' goals. For us, the question is in what situations - and for whom — is an absolute ranking of groups desirable, and in what circumstances — and for whom — is such a ranking a detriment vis-à-vis a relative ranking scheme. ${ }^{1}$

The next section first describes the model. It implements the relative and absolute decision rules in the context of the model, and compares the implications for each of the concerned parties. A concluding section follows.

\footnotetext{
1 This is an implementation of the paper on Aid allocation developed by Epstein and Gang (2009b) into the type of questions asked and discussed in Epstein and Gang (2009a).
} 


\section{The Model}

Consider the case where there exist $m$ groups in the immigrant society that have partly overlapping programs. Each group has the same objective in terms of helping and finding solutions to problems of their society. Each obtains a reward for helping their fellow immigrants. The reward is a grant (or grants) from the foundation.

The maximum reward group $i(i=1,2)$ receives by helping its countrymen is $n_{i}$, where $n_{i}$ can be greater or smaller than $n_{j}$ for all $j \neq i$, depending on which group has more to gain. In probabilistic terms, the probability that group $i$ wins the contest and receives a grant of $n_{i}$ is equal to $P r_{i}$. The expected grant group $i$ receives from this contest is $P r_{i} n_{i}$. Alternatively, we can think of $\operatorname{Pr}_{i}$ as the proportion of the grant (or a proportion of the grants rewarded) this group receives in the competition. We talk generally about proportions of the grant obtained and not probabilities of winning the contest, keeping in mind that the two are equivalent.

Groups invest effort trying to help immigrant society. Effort, $x_{i}$, can be seen as a monetary value, time, effort, etc. and we assume that the cost of each unit of effort is one unit. Own effort, the efforts invested by the other group, the stakes and the contest success function; determine the probability of winning the contest.

Let $w$ denote the net payoff received by a group. The expected net payoff (surplus) for the risk neutral group is given by

$$
E\left(w_{i}\right)=\operatorname{Pr}_{i} n_{i}-x_{i} \forall i=1,2, \ldots, m
$$

We assume that the proportion of the grant obtained in the contest (or the probability of winning the contest) satisfies the following conditions:

(i) The sum of the proportions of the grant obtained equals one, $\sum_{i=1}^{m} \operatorname{Pr}_{i}=1$. This means that the foundation will only give one of the groups the grant. An alternative explanation would be that both groups get credit for what they did and as such obtain a proportion of the grant they could have won if there was only one group winning.

(ii) As a group $i$ increases its effort, it obtains a higher proportion of the grant, $\frac{\partial \operatorname{Pr}_{i}}{\partial x_{i}}>0$. 
(iii) As group $j$, the opponent of group $i$, increases its effort, the proportion of the grant that group $i$ obtains decreases, $\frac{\partial \operatorname{Pr}_{i}}{\partial x_{j}}<0$.

(iv) The marginal increase in the proportion of the grant obtained from the contest decreases with investment in effort, $\frac{\partial^{2} \operatorname{Pr}_{i}}{\partial x_{i}{ }^{2}}<0$ (this inequality ensures that the second order conditions for maximization are satisfied).

(v) To simplify, we do not discuss the possibility of free riding for the different groups. One could think of a situation under which the actions of one group positively affect the proportion obtained by the other group, as the people do not always know which of the groups was really responsible for the outcome. We overcome this by assuming $\frac{\partial \operatorname{Pr}_{i}}{\partial x_{i}}>0$ and $\sum_{i=1}^{m} \operatorname{Pr}_{i}=1$

The function $\operatorname{Pr}_{\mathrm{i}}($.$) is usually referred to as a contest success function (CSF). The functional$ forms of the CSF's commonly assumed in the literature satisfy these assumptions (see Nitzan, 1994).

The groups engage in a contest and we assume a Nash equilibrium outcome. Each group determines the level of its activities $x_{i}$ so that its expected payoff, $E\left(w_{i}\right) \forall i=1,2, . ., m$, is maximized. The first order condition for maximization is given by

$$
\frac{\partial E\left(w_{i}\right)}{\partial x_{i}}=\frac{\partial \operatorname{Pr}_{i}}{\partial x_{i}} n_{i}-1=0_{i}
$$

Equation (2) is satisfied if and only if

$$
\frac{\partial \operatorname{Pr}_{i}}{\partial x_{i}}=\frac{1}{n_{i}}
$$

Thus, given that the proportion has decreasing marginal utility with respect to the level of effort invested, the group with the higher benefit from the contest will invest more effort in the contest. 
For example, if group 1 has the higher benefit in the contest compared to group $2, n_{1}>n_{2}$, then group 1 will determine its effort, $x_{1}$, such that the marginal proportions are $\frac{\partial \operatorname{Pr}_{1}}{\partial x_{1}}<\frac{\partial \operatorname{Pr}_{2}}{\partial x_{2}}$, in order to increase its proportion of the grant. The group that has a higher benefit from winning the contest will invest the highest amount of effort.

To simplify and without loss of generality assume that:

$$
n_{1} \geq n_{2}>n_{3} \geq \ldots \geq n_{m}
$$

This assumption simply states that there are two groups that have higher stakes than all the rest of the groups.

We now describe two highly stylized (extreme) regimes, (1) absolute ranking, and (2) relative ranking. In the Absolute ranking we have one winning group even though both groups helped immigrant society. Here the winner of the contest obtains all the grant. On the other hand, in Relative ranking the two groups divide the grants relative to their achievements. These situations do not simultaneously coexist. However, comparing their outcomes provides useful insights, and we compare them after fully detailing each of the scenarios.

\section{The Absolute Ranking}

This ranking states that the group investing the largest amount of effort wins the grant. This type of contest is defined by using the all pay auction, and here thinking in terms of the probability of winning the contest enhances our intuition. In the absolute ranking the probability of winning is a function of the efforts invested by groups or the efforts perceived by the foundation. (Note that in equilibrium the efforts will be a function of the grants the groups can obtain). In the absolute ranking the probability of winning is 


$$
\operatorname{Pr}_{i}=\left\{\begin{array}{l}
1 \quad \text { if } \quad x_{i}>x_{j} \forall i \neq j \\
\frac{1}{k} \quad \text { if } i \text { ties for the high bid with } k-1 \text { others } \\
0 \quad \text { if } \quad x_{j}>x_{i} \forall i \neq j
\end{array}\right.
$$

It can be verified that there exists a unique symmetric Nash equilibrium as well as a continuum of asymmetric Nash equilibria. In any equilibrium, groups 3 through $m$ invest zero effort in activities with probability one (see Baye, Kovenock, and de Vries, 1996), so that only the two groups who make the greatest efforts will participate. We conduct our analysis for two groups, groups 1 and 2. Without loss of generality, assume that $n_{1}>n_{2}$; thus group 1 has greater gain from winning the contest. It is clear, therefore, that group 1 is able to bid more than group 2. However, it is not clear how much each will bid in equilibrium.

Based on these findings, we can obtain equilibrium expected expenditures, equilibrium probabilities and expected payoffs.

Since the efforts of the two groups are random variables, it is clear that the probability that $x_{i}=x_{j}$ equals zero $\left(P\left(x_{i}=x_{j}\right)=0\right)$ (see Cohen and Sela (2007)). Thus in the case of only two groups the probability of winning the grant becomes

$$
\operatorname{Pr}_{i}=\left\{\begin{array}{lll}
1 & \text { if } & x_{i}>x_{j} \\
0 & \text { if } & x_{j}>x_{i}
\end{array} .\right.
$$

The expected activity level for each group is (see appendix for calculations)

$$
E\left(x_{1}^{*}\right)=\frac{n_{2}}{2} \text { and } E\left(x_{2}^{*}\right)=\frac{n_{2}^{2}}{2 n_{1}} \text {. }
$$

The equilibrium probability of winning the contest for each group equals 


$$
\operatorname{Pr}_{1}^{*}=\frac{2 n_{1}-n_{2}}{2 n_{1}} \text { and } \operatorname{Pr}_{2}^{*}=\frac{n_{2}}{2 n_{1}}
$$

The expected equilibrium payoff for each group equals

$$
E\left(w_{1}^{*}\right)=n_{1}-n_{2} \quad \text { and } \quad E\left(w_{2}^{*}\right)=0
$$

In equilibrium, the total amount of activities carried out by the groups' equals

$$
E\left(X^{*}\right)=E\left(x_{i}^{*}+x_{j}^{*}\right)=\frac{n_{2}^{2}+n_{2} n_{1}}{2 n_{1}}=\frac{n_{2}\left(n_{2}+n_{1}\right)}{2 n_{1}} .
$$

Notice that if both groups can obtain the same benefit, $n_{1}=n_{2}=n$, the expenditure of each group is $E\left(x_{1}^{*}\right)=\frac{n}{2}$ and $E\left(x_{2}^{*}\right)=\frac{n}{2}$; the probability of winning for each equals one-half, $\operatorname{Pr}_{1}^{*}=\operatorname{Pr}_{2}^{*}=\frac{1}{2}$; the expected payoff for each group is zero, $E\left(w_{1}^{*}\right)=E\left(w_{2}^{*}\right)=0$; and the total effort invested equals $X^{*}=n$.

\section{The Relative ranking}

Here we consider the case when groups compete with one another in a contest in which there is no single winner. Later we will compare the two extreme cases with one another: the Absolute ranking with the Relative ranking.

Without a winner taking all the grant each group fights to obtain its maximum possible portion. We assume that the contest is characterized by the relative ranking (Lockard and Tullock, 2001), $\operatorname{Pr}_{i}=\frac{x_{i}^{r}}{x_{j}{ }^{r}+x_{i}^{r}}$ for $r \leq 2$. The return to effort in this lottery function is captured by the parameter $r$. When $r$ approaches infinity the relative ranking becomes the absolute ranking under which the group that invests in the highest level of activities wins the contest (see Baye, Kovenock and de Vries, 1993, 1996). The idea behind this is that the group with the higher benefit has a weight of infinity and thus will win with probability one and the 
group with the lower stake will lose with probability one.

For now we assume that $r$ is known and fixed and $r \leq 2$. The expected net payoff (surplus) for the risk neutral group is thus given by

$$
E\left(w_{i}\right)=\frac{x_{i}^{r}}{x_{i}^{r}+x_{j}^{r}} n_{i}-x_{i} \quad \forall i=1,2 \text {. }
$$

The first order condition, as stated in equation (2), which ensures that the group maximizes its expected payoff, is given by

$$
\frac{\partial E\left(w_{i}\right)}{\partial x_{i}}=\frac{r x_{i}^{r-1} x_{j}^{r}}{\left(x_{i}^{r}+x_{j}^{r}\right)^{2}} n_{i}-1=0 \quad \forall i, j=1,2 i \neq j
$$

Denote by $x_{i}^{*} \quad \forall i, j=1,2 i \neq j$ the Nash equilibrium outcome of the contest. Solving (12) for both groups using a Nash equilibrium, we obtain that the level of activities each group participates in equals ${ }^{2}$

$$
x_{i}^{*}=\frac{r n_{i}^{r+1} n_{j}^{r}}{\left(n_{i}^{r}+n_{j}^{r}\right)^{2}} \quad \forall i, j=1,2 \quad i \neq j
$$

2 We obtain from the first order conditions (equation (12)) that $\forall i, j=1,2 i \neq j, \frac{r x_{i}^{r-1} x_{j}^{r}}{\left(x_{i}^{r}+x_{j}^{r}\right)^{2}} n_{i}=1$, therefore it holds that $\frac{r x_{1}^{r-1} x_{2}^{r}}{\left(x_{1}^{r}+x_{2}{ }^{r}\right)^{2}} n_{1}=1$ and $\frac{r x_{2}^{r-1} x_{1}^{r}}{\left(x_{1}^{r}+x_{2}^{r}\right)^{2}} n_{2}=1$. Using these two equations we obtain that $\frac{x_{2}}{x_{1}} \frac{n_{1}}{n_{2}}=1$ and thus $x_{2}=x_{1} \frac{n_{2}}{n_{1}}$. Substituting $x_{2}\left(x_{2}=x_{1} \frac{n_{2}}{n_{1}}\right)$ into $\frac{r x_{1}^{r-1} x_{2}^{r}}{\left(x_{1}^{r}+x_{2}^{r}\right)^{2}} n_{1}=1$ we obtain that $x_{1}^{*}=\frac{r n_{1}^{r+1} n_{2}^{r}}{\left(n_{1}^{r}+n_{2}^{r}\right)^{2}}$. In a similar way we calculate the optimal level of $x_{2}$. 
We can also think of this terms of the proportion of the grants obtained from the contest. Therefore, the Nash equilibrium proportion of the grants obtained in the contest equals

$$
\operatorname{Pr}_{i}^{*}=\frac{n_{i}^{r}}{n_{i}^{r}+n_{j}^{r}} \quad \forall i, j=1,2 i \neq j
$$

The expected equilibrium payoff for each group equals

$$
E\left(w_{i}^{*}\right)=\frac{n_{i}^{r}}{n_{i}^{r}+n_{j}^{r}} n_{i}-\frac{r n_{i}^{r+1} n_{j}^{r}}{\left(n_{i}^{r}+n_{j}^{r}\right)^{2}}=\frac{n_{i}^{2 r+1}-(r-1) n_{i}^{r+1} n_{j}^{r}}{\left(n_{i}^{r}+n_{j}^{r}\right)^{2}} \forall i, j=1,2, i \neq j, r<2 .
$$

And finally, we can calculate the total amount of effort invested in the contest by the two groups. In the literature this measure is called grant dissipation and usually has a negative connotation, i.e. the contest designer tries to decrease the grant dissipation. Here grant dissipation can be seen in a positive light as it helps the country needing help. We denote this total effort in equilibrium by $X^{*}$ :

$$
X^{*}=x_{i}^{*}+x_{j}^{*}=\frac{r n_{i}^{r} n_{j}^{r}\left(n_{i}+n_{j}\right)}{\left(n_{i}^{r}+n_{j}^{r}\right)^{2}} \quad \forall i, j=1,2 i \neq j .
$$

In the case where the groups are symmetric, i.e., $n_{1}=n_{2}=n$, we would obtain the following: the level of activities of each group equals $x_{i}^{*}=n \frac{r}{4} \quad \forall i, j=1,2 i \neq j$ (remember that $\mathrm{r}$ is less than or equal to 2 and therefore the total expenditure will be at the maximum when $x_{i}^{*}=\frac{n_{i}}{2}$ ); the Nash equilibrium proportion of the grants obtained from the contest will be equal to one-half, $\operatorname{Pr}_{i}^{*}=\frac{1}{2} ;$ the expected equilibrium payoff to each group equals $\frac{(2-r) n}{4}$ (once again, 
remember that $r$ is less than or equal to 2$),{ }^{3}$ and finally the total effort in equilibrium equals $X^{*}=\frac{r n}{2}$.

Let us consider how changes in $r$ affect the expected equilibrium payoff, $E\left(w_{i}^{*}\right)=\frac{n_{i}^{r}}{{n_{i}}^{r}+n_{j}{ }^{r}} n_{i}-\frac{r n_{i}^{r+1} n_{j}^{r}}{\left(n_{i}{ }^{r}+n_{j}{ }^{r}\right)^{2}}=\frac{n_{i}^{2 r+1}-(r-1) n_{i}^{r+1} n_{j}^{r}}{\left(n_{i}{ }^{r}+n_{j}{ }^{r}\right)^{2}} \forall i, j=1,2, i \neq j, r<2$, and how total effort is affected in equilibrium, $X^{*}=x_{i}^{*}+x_{j}^{*}=\frac{r n_{i}^{r} n_{j}^{r}\left(n_{i}+n_{j}\right)}{\left(n_{i}^{r}+n_{j}^{r}\right)^{2}} \quad \forall i, j=1,2 i \neq j$. To simplify our calculations denote by $a$ the relative benefit of the second group receiving the grant in relationship to that of the first group receiving the grant: $a=\frac{n_{2}}{n_{1}}$. Given $a$ we recalculate the expected payoff and total effort in equilibrium as

$$
\begin{aligned}
& E\left(w_{i}^{*}\right)=\frac{n_{i}\left(1-(r-1) a^{r}\right)}{\left(1+a^{r}\right)^{2}} \text { and } X^{*}=\frac{r n a^{r}(1+a)}{\left(1+a^{r}\right)^{2}} \quad \forall a=\frac{a_{j}}{a_{i}}, i=1,2, r<2, \\
& \text { where, } \quad \frac{\partial E\left(w_{i}^{*}\right)}{\partial r}=\frac{n_{i}\left(1+a^{2 r}\left(1+\left(r-r^{2}\right) \operatorname{Ln}(a)\right)+r a^{r}\left(2+\left(r^{2}-3\right) \operatorname{Ln}(a)\right)\right)}{\left(1+a^{r}\right)^{2}}
\end{aligned}
$$

and $\frac{\partial X^{*}}{\partial r}=\frac{n a^{r}(1+a)\left(1+r \operatorname{Ln}(a)+a^{r}(1-r \operatorname{Ln}(a))\right)}{\left(1+a^{r}\right)^{3}}$. As we can see from the above, the effect of a change in the parameter $r$ has an ambiguous affect on the expected payoff and expenditure of the groups. For example, without loss of generality assume that $a<1$. Since $\operatorname{Ln}(a)<0$ then for $1<r<\sqrt{3}, \frac{\partial E\left(w_{i}^{*}\right)}{\partial r}>0$ and for $\mathrm{a}=1, \frac{\partial E\left(w_{i}^{*}\right)}{\partial r}>0$ and $\frac{\partial X^{*}}{\partial r}>0$. For $\mathrm{r}<1$ it holds that $\frac{\partial X^{*}}{\partial r}>0$

3 For $r>2$ the equilibrium differs from this one as it is based on mixed and not pure strategies. This is the case in the all pay auction that we previously described. 


\section{Comparing the investment of effort of the groups under Both Situations}

The groups do not have a choice between the Absolute ranking and Relative ranking contests we model above. They face what they face. Over time what they face may change, and we are interested in the outcomes of each of the situations. We now compare these two types of contests from the perspectives of the groups, immigrant society, and the foundation. $X^{*}$ gives the aggregate activity of the groups in equilibrium (for the case of stakes that do not depend on the efforts invested by the contestants, see Epstein and Nitzan, 2006a, 2006b, 2007).

Under the relative ranking, $\operatorname{Pr}_{i}=\frac{x_{i}^{r}}{x_{j}^{r}+x_{i}^{r}}$ for $r \leq 2$, from (16) we obtain that the total amount of activities carried out is equal to $X_{L}^{*}=x_{i}^{*}+x_{j}^{*}=\frac{r n_{i}^{r} n_{j}^{r}\left(n_{i}+n_{j}\right)}{\left(n_{i}^{r}+n_{j}^{r}\right)^{2}} \quad \forall i, j=1,2 i \neq j$. In order to simplify our analysis let us assume that $r=1$ (remember that the values that $r$ can take on in this case are between two and zero). Under the absolute ranking, from equation (10) we obtain that the total investment into activities is equal to $E\left(X_{p}^{*}\right)=\frac{n_{2}\left(n_{2}+n_{1}\right)}{2 n_{1}}$.

The total amount of expenditure invested in the contest is higher under the relative ranking than under the absolute ranking regime if

$$
X_{L}^{*}=\frac{n_{2} n_{1}}{n_{1}+n_{2}}>\frac{n_{2}\left(n_{2}+n_{1}\right)}{2 n_{1}}=E\left(X_{p}^{*}\right)
$$

Equation (17) holds if and only if

$$
n_{1}^{2}-2 n_{1} n_{2}-n_{2}>0
$$

From (18) we may conclude that the total amount of expenditure invested in the contest by the different groups is higher under the relative ranking rather than under the absolute ranking regime if 


$$
n_{1}>n_{2}(1+\sqrt{2})
$$

Since, by assumption, $n_{1} \geq n_{2}$, the result tells us that in order for the lottery contest to be worse for the receiving, the grant that one of the groups can obtain from such actions must be larger than the other group's grant (more than twice as large). We summarize this result in the following proposition:

If the variance of grants that can be generated by helping immigrant society is sufficiently large, i.e., $\frac{n_{1}}{n_{2}}>1+\sqrt{2}$, then the foundation-- which is interested in maximizing the total effort of the groups -- prefers that the absolute ranking contest where the group that invests the most effort wins. If each group has the same stake, i.e., $n_{1}=n_{2}$, then the foundation prefers the relative ranking.

In order to analyze the preferences of the groups we must compare their expected payoffs under both the relative ranking and the absolute ranking regime. Remember that we assumed, without loss of generality, that group 1 has at least as large a stake as the $\operatorname{second}$ group $\left(n_{1} \geq n_{2}\right)$. The groups prefer the regime that generates for them the maximum expected equilibrium payoff, $E\left(w_{i}^{*}\right)$. Under the relative ranking, and again assuming $r=1$, the expected equilibrium payoff for group 2 (the weaker player) equals $E\left(w_{2}^{*}\right)=\frac{n_{2}{ }^{3}}{\left(n_{1}+n_{2}\right)^{2}}$, while the expected equilibrium under the absolute ranking equals zero, $E\left(w_{2}^{*}\right)=0$. Therefore it is clear that,

The weaker group, the group that has less to gain from helping its countrymen, always prefers the relative ranking system.

For the stronger group the expected equilibrium payoff under the relative ranking equals 
$E_{L}\left(w_{1}^{*}\right)=\frac{n_{1}^{3}}{\left(n_{1}+n_{2}\right)^{2}}$, while the expected equilibrium under the absolute ranking equals $E_{P}\left(w_{1}^{*}\right)=n_{1}-n_{2}$. The expected payoff for group 1 under the relative ranking regime is greater than that obtained under the absolute ranking regime and thus this group prefers the relative ranking regime if

$$
E_{L}\left(w_{1}^{*}\right)=\frac{n_{1}^{3}}{\left(n_{1}+n_{2}\right)^{2}}>n_{1}-n_{2}=E_{P}\left(w_{1}^{*}\right)
$$

Equation (20) holds if and only if

$$
n_{1}^{2}-2 n_{1} n_{2}-n_{2}<0
$$

From equation (21) we may conclude that the expected payoff in the contest and efforts made are higher under the relative ranking rather than under the absolute ranking regime if

$$
0<n_{1}<n_{2}(1+\sqrt{2})
$$

In other words,

The group with the higher stake, with more to gain from helping their countrymen, prefers the relative ranking to an absolute ranking if the difference between the groups is not sufficiently large, $\frac{n_{1}}{n_{2}}<1+\sqrt{2}$.

Note that the interests of foundation and the strongest group always align. 


\section{CONCLUSION}

In our society there exists a foundation that has resources and that wishes to help migrants. In order to help migrants the foundation needs grass roots organizations to invest their efforts in helping migrants (for example in the USA the McArthur Foundation and the Ford Foundation that want to help immigrants.) The foundation announces a prize (grant) for which the groups compete. The competition is such that the one that invests more resources in helping the migrants has a higher probability of winning and obtaining more resources. The question is, how the foundation elicits the most effort from the different "grass roots" groups.

In a highly structured and simple model we characterize and compare two ex ante regimes: (1) the absolute reward scheme presented by an all-pay auction in which the winner takes all available grants; (2) the relative reward scheme in which the grant allocation rule is a lottery and each group obtains a proportion of the grants. In the former regime the equilibrium is in mixed strategies, the "stronger" group could actually lose the contest and get nothing. However, the expected payoff for the weaker group is zero.

The contests we address are the fractious relationships among groups seeking to increase their expected payoff. We are able to derive a very specific condition allowing us to see when each of the concerned parties wins and when each loses their contests. If the difference between the groups in terms of the rewards they can obtain from helping the country is not sufficiently large, all parties - the two groups and the foundation itself - prefer the lottery regime relative ranking to an absolute ranking. However, if the difference between the groups in terms of the rewards that can be obtained is sufficiently large, then the group with the low benefit, group 2, prefers the relative ranking regime while the other group and the foundation prefer the absolute ranking.

The contests we address are the fractious relationships among groups seeking help their immigrant society. Aside from the insights we are able to provide about the reward ranking scheme, our work is further distinguished by accounting for: (i) the possibility of recipient activities that can change the groups' ordering of the regimes, and (ii) recipients gain based on reward regime. 


\section{REFERENCES}

Alesina, Alberto and Eliana La Ferrara, 2000, Participation in Heterogeneous Communities, Quarterly Journal of Economics, (August), 847-904.

Altonji, J. G. and R. M. Blank, 1999, Race and Gender in the Labor Market, in O. Ashenfelter and D.Card (eds.), Handbook of Labor Economics, vol. 3C, Elsevier Science B.V.:Amsterdam, 3143-3259.

Anas, Alex, 2002, Prejudice, Exclusion and Compensating Transfers: The Economics of Ethnic Segregation, Journal of Urban Economics, 52 (3), 409-32.

Bauer, Thomas, Gil S. Epstein and Ira N. Gang, 2005, Enclaves, Language and the Location Choice of Migrants, Journal of Population Economics, 18 (4), 649-662.

Baye, M.R., Kovenock, D. and de Vries, C.G. (1993) Rigging the lobbying process: an application of the all-pay auction. American Economic Review 83(1), 289-294.

Bisin, Alberto and Thierry Verdier, 2000, "Beyond the Melting Pot": Cultural Transmission, Marriage, and the Evolution of Ethnic and Religious Traits, Quarterly Journal of Economics, August, 955-988.

Blau, F. D. and L. M. Kahn, 1997, Swimming Upstream: Trends in the Gender Wage Differential in the 1980s, Journal of Labor Economics, 15 (1), 1- 42.

Blau, Francine D. and Lawrence M. Kahn, 2006, The US Gender Pay Gap in the 1990s: Slowing Convergence, Industrial and Labor Relations Review, 60 (1), 45-66.

Blau, Francine D. and Lawrence M. Kahn, 2007, The Gender Pay Gap, The Economists' Voice: Vol. 4 : Iss. 4, Article 5. Available at: http://www.bepress.com/ev/vol4/iss4/art5.

Bun, Chan Kwok and Tong Chee Kiong, 1993, Rethinking Assimilation and Ethnicity: The Chinese in Thailand, International Migration Review, 27 (1), 140-168.

Chiswick BR, Miller PW, 1995, The Endogeneity between Language and Earnings: International Analyses, Journal of Labor Economics 13: 246-288.

Chiswick BR, Miller PW, 1996, Ethnic Networks and Language Proficiency among Immigrants, Journal of Population Economics 9: 19-36.

Chiswick, B. R., 1977, Sons of Immigrants: Are They at an Earnings Disadvantage?, American Economic Review, Papers and Proceedings, 376-380.

Cohen C. and A. Sela 2007 Contests with Ties, The B.E. Journal of Theoretical Economics, Vol. 7, Iss. 1. (Contributions), Article 43.

Constant, A., Gataullina L. and K.F. Zimmermann, 2008, "Ethnosizing Immigrants" Journal of Economic and Behavioral Organization, forthcoming.

Deutsch, Joseph, Gil S. Epstein and Tikva Lecker, 2006, Multi-Generation Model of Immigrant Earnings: Theory and Application, Research in Labor Economics, 217-234.

Dustmann, Christian, Francesca Fabbri, and Ian Preston, 2004, Ethnic Concentration, Prejudice and Racial Harassment of Minorities, CReAM Discussion Paper 05/04 (www.econ.ucl.ac.uk/cream/).

Ellingsen, T. (1991) Strategic buyers and the social cost of monopoly. American Economic Review 81(3), 648-657.

Epstein, Gil S. and Ira N. Gang, (2009a) "Ethnicity, Assimilation and Harassment in the Labor Market", Research in Labor Economics 79, 67-90. 
Epstein, Gil S. and Ira N. Gang, (2009b) "Good Governance and Good Aid Allocation", Journal of Development Economics, Volume 89, Issue 1, May, 12-18.

Epstein, Gil S. 2003, Labor Market Interactions between Legal and Illegal Minorities, Review of Development Economics, 7(1), 2003, 30-43.

Epstein, Gil S. and Ira Gang, 2006, "Ethnic Networks and International Trade", in Labor Mobility and the World Economy Federico Foders and Rolf J. Langhammer (ed), Springer (Berlin, Heidelberg), 85-103.

Epstein, Gil S. and Shmuel Nitzan, 2006a, "Reduced Prizes and Increased Effort in Contests", Social Choice and Welfare 26(3), 447-453.

Epstein, Gil S. and Shmuel Nitzan, 2007 Endogenous Public Policy and Contests. Springer.

Epstein, Gil S.. and Nitzan, S. (2006b) Effort and performance in public policy contests. Journal of Public Economic Theory 8(2), 265-282.

Epstein, Gil S.. and Nitzan, S. (2007) Endogenous Public Policy and Contests, Springer.

Gang, Ira N. and Klaus F. Zimmermann, 2000, Is Child Like Parent? Educational Attainment and Ethnic Origin, Journal of Human Resources, 35, 550-569.

Gang, Ira N. and Rivera-Batiz, Francisco, 1994, Labor Market Effects of Immigration in the United States and Europe: Substitution vs. Complementarity, Journal of Population Economics, 7, 157-175.

Gang, Ira N., Francisco Rivera-Batiz and, Myeong-Su Yun, 2002, Economic Strain, Ethnic Concentration and Attitudes Towards Foreigners in the European Union, IZA Discussion Paper 578 (www.iza.org).

Gang, Ira N., Francisco Rivera-Batiz and, Myeong-Su Yun, 2010, Changes in Attitudes towards Immigrants in Europe: Before and After the Fall of the Berlin Wall, this volume.

Hillman, A.L. and Riley, J.G. (1989) Politically contestable rents and transfers. Economics and Politics 1(1), 17-39.

Kahanec, Martin, 2006, Ethnic Specialization and Earnings Inequality: Why Being a Minority Hurts but Being a Big Minority Hurts More, IZA Discussion Paper 2050, (www.iza.org).

Lazear, Edward P., 1999, Culture and Language, Journal of Political Economy, 107 (6, pt. 2), S95-S126.

Lockard, A.A and Tullock, G. eds. (2001) Efficient rent-seeking, chronicle of an intellectual quagmire. Boston: Kluwer Academic Publishers.

Nitzan, S. (1994) Modelling rent-seeking contests. European Journal of Political Economy 10(1), 41-60 (also appears in Lockard and Tullock, 2001).

Smith, J.P. and F.R. Welch, 1989, Black Economic Progress after Myrdal, Journal of Economic Literature, 27 (2), 519-64. 


\section{Appendix}

It is a standard result that there are no pure strategy equilibria in all-pay auctions (Hillman and Riley (1989), Ellingsen (1991) and Baye, Kovenock and de Vries (1993, 1996)). Suppose group 2 bids $0<x_{2} \leq n_{2}$. Then the first group's optimal response is $x_{1}=x_{2}+\varepsilon<n_{1}$ (i.e., marginally higher than $x_{2}$ ). But then $x_{2}>0$ cannot be an optimal response to $x_{1}=x_{2}+\varepsilon$. Also, it is obvious that $x_{1}=x_{2}=0$ cannot be an equilibrium. Hence, there is no equilibrium in pure strategies. There is a unique equilibrium in mixed strategies given by the following cumulative distribution functions (see Hillman and Riley (1989), Ellingsen (1991) and Baye, Kovenock, and de Vries, 1996)): $G_{1}\left(x_{1}\right)=\frac{x_{1}}{n_{2}}$ for $x_{1} \in\left[0, n_{2}\right)$ and $G_{2}\left(x_{2}\right)=1-\frac{n_{2}}{n_{1}}+\frac{x_{2}}{n_{1}}$ for $x_{2} \in\left[0, n_{2}\right)$. The equilibrium c.d.f's show that group 1 bids uniformly on $\left[0, n_{2}\right]$, while group 2 puts a probability mass equal to $\left(1-n_{2} / n_{1}\right)$ on $x_{2}=0$. The expected investment expenditures are $E\left(x_{1}\right)=\int_{0}^{n_{2}} x_{1} d G_{1}\left(x_{1}\right)=\frac{n_{2}}{2}$ and $E\left(x_{2}\right)=\int_{0}^{n_{1}} x_{2} d G_{2}\left(x_{2}\right)=\frac{n_{2}^{2}}{2 n_{1}}$. Note, we think of the all-pay auction as probabilistic - i.e., the stronger group is more likely to win the contest. 